\title{
Article \\ Preharvest Treatment of Methyl Jasmonate and Salicylic Acid Increase the Yield, Antioxidant Activity and GABA Content of Tomato
}

\author{
Min Woo Baek ${ }^{1,2}{ }^{1}$, Han Ryul Choi ${ }^{1,2}$, Lee Yun Jae ${ }^{3}$, Ho-Min Kang ${ }^{1,2}{ }^{(D}$, Ok-Hwan Lee ${ }^{4}(\mathbb{D}$, \\ Cheon Soon Jeong $1,2, *$ (D) and Shimeles Tilahun $1,5,6, *$ (D) \\ 1 Department of Horticulture, Kangwon National University, Chuncheon 24341, Korea; \\ minwoo100@kangwon.ac.kr (M.W.B.); hanryul192@kangwon.ac.kr (H.R.C.); \\ hominkang@kangwon.ac.kr (H.-M.K.) \\ 2 Interdisciplinary Program in Smart Agriculture, Kangwon National University, Chuncheon 24341, Korea \\ 3 Department of Agriculture and Life Industry, Kangwon National University, Chuncheon 24341, Korea; \\ lbk45kj@naver.com \\ 4 Department of Food Science and Biotechnology, Kangwon National University, Chuncheon 24341, Korea; \\ loh99@kangwon.ac.kr \\ 5 Agriculture and Life Science Research Institute, Kangwon National University, Chuncheon 24341, Korea \\ 6 Department of Horticulture and Plant Sciences, Jimma University, Jimma 378, Ethiopia \\ * Correspondence: jeongcs@kangwon.ac.kr (C.S.J.); shimeles@kangwon.ac.kr (S.T.); \\ Tel.: +82-033-2506409 (C.S.J.)
}

check for updates

Citation: Baek, M.W.; Choi, H.R.; Yun Jae, L.; Kang, H.-M.; Lee, O.-H.; Jeong, C.S.; Tilahun, S. Preharvest Treatment of Methyl Jasmonate and Salicylic Acid Increase the Yield, Antioxidant Activity and GABA Content of Tomato. Agronomy 2021, 11, 2293. https://doi.org/10.3390/ agronomy11112293

Academic Editor: Luis NogueraArtiaga

Received: 15 October 2021

Accepted: 11 November 2021

Published: 12 November 2021

Publisher's Note: MDPI stays neutral with regard to jurisdictional claims in published maps and institutional affiliations.

Copyright: (C) 2021 by the authors. Licensee MDPI, Basel, Switzerland. This article is an open access article distributed under the terms and conditions of the Creative Commons Attribution (CC BY) license (https:// creativecommons.org/licenses/by/ $4.0 /)$.

\begin{abstract}
This study investigated the effect of preharvest treatment of $0.25 \mathrm{mM}$ methyl jasmonate (MeJA) and $0.5 \mathrm{mM}$ salicylic acid (SA) on quality parameters, most important secondary metabolites (lycopene, $\beta$-carotene, ascorbic acid, total phenolics, and flavonoids), antioxidant activities, and amino acid contents of 'Kumato' tomato. Treatments with MeJA and SA led to an increase of total yield per plant and were effective in maintaining the fruit quality attributes such as firmness, total soluble solids, titratable acidity, and Brix acid ratio at two maturity stages (S1 and S2). In addition, lycopene, $\beta$-carotene, ascorbic acid, total phenolics, and flavonoids were significantly higher in the treated fruit than in the control. Moreover, $\gamma$-aminobutyric acid (GABA), essential amino acids, and antioxidant activity increased due to MeJA and SA treatments at both stages, especially with MeJA treatment at S2. Overall results also showed the effectiveness of MeJA treatment than SA on improving the yield and nutritional quality of 'Kumato' tomato.
\end{abstract}

Keywords: antioxidant activity; ABTS; DPPH; FRAP; GABA; methyl jasmonate; salicylic acid

\section{Introduction}

Tomato (Solanum lycopersicum L.) is one of the most popular vegetables that belong to the Solanaceae (nightshade) family. According to FAOSTAT [1], the world production of the crop is 180.77 million tons from 5.03 million ha, and Asia holds 112.10 million tons (62\%) of the production share. The production in the Republic of Korea in 2019 was 420,573 tons from 6460 ha of land [1].

Ripening of tomato fruit involves the transformation of chloroplasts to chromoplasts [2] which result in the accumulation of linear carotene (lycopene) and its orange cyclization pro-vitamin A product ( $\beta$-carotene) [2]. These pigments play a major role in the protection of plants against photo-oxidative processes and they are efficient antioxidants scavenging singlet molecular oxygen and peroxyl radicals [3]. Tomatoes also contain phenolic compounds which enhance their antioxidant properties [4]; and flavonoids are the major phenolics in tomatoes [5]. Moreover, tomato fruit contains moderate amounts of ascorbic acid that contribute to the recommended daily allowance of vitamin C [4].

$\gamma$-Aminobutyric acid (GABA) is a four-carbon non-proteinogenic amino acid that is widely found in plants, animals, and bacteria [6]. GABA has received much attention as a 
health-promoting functional compound due to its roles as an inhibitory neurotransmitter in the central nervous system [7] and it reduces blood pressure, induces relaxation, and improves immunity when administered orally [8]. In plants, GABA is primarily metabolized through the GABA shunt pathway which is involved in many physiological responses such as defense against insects, protection from oxidative stresses, and response to diverse stimuli including heat shock and phytohormones [8]. A high level of GABA was found to accumulate in tomato fruit before the breaker stage and catabolized rapidly thereafter [6]. Nevertheless, the color of 'Kumato' that we used for this study is ranging from green to reddish-brown or purple after ripening and assumed to retain a high level of GABA after breaker stages.

Abiotic factors such as rainfall, solar radiation, and temperature and biotic factors like herbivore or pathogen attacks can influence the phytochemical composition [9]. Recent studies also reported that the exogenous preharvest treatment of methyl jasmonate (MeJA) and salicylic acid (SA) mimic biotic stress and increase the phytochemical compounds in different crops [9-11]. MeJA is a certified safe compound for all food commodities when applied before harvest [12]. Similarly, SA concentrations ranging from micromolar $(\sim 100 \mu \mathrm{M})$ to low millimolar $(<2 \mathrm{mM})$ are safe, and effective concentrations need to be determined for specific crops [13].

Generally, the response of plants to the stress caused by the exogenous treatments of elicitors like MeJA and SA increases the synthesis of phytochemical compounds and improves nutraceutical attributes $[10,14]$. Besides, the bioactive compounds and synergistic interactions between them influence the antioxidant activity and disease-preventing potential of tomatoes [4]. Daily intake of tomatoes and their derivatives has the potential to lower the risk of many forms of cancer and cardiovascular diseases because of the protective effect of the antioxidants [15]. Based on these previous reports, we hypothesized that nutritional quality of tomatoes could be improved with the exogenous preharvest application of MeJA and SA. Therefore, the present study sought to determine whether these treatments enhance the antioxidant properties (lycopene, $\beta$-carotene, ascorbic acid, total phenolics, and flavonoids), antioxidant activities, and amino acid contents (mainly GABA) of 'Kumato' tomato.

\section{Materials and Methods}

\subsection{Plant Material and Harvesting Stages}

'Kumato' tomato that assumed to retain a high level of GABA after maturity was grown in a climate-controlled greenhouse with hydroponics growing system in Gangwon province, Republic of Korea, in spring/summer 2020. The electrical conductivity (EC) of fertigation solution was adjusted at 2.0 to 2.2 deci Siemens per meter $\left(\mathrm{dS} \mathrm{m}^{-1}\right)$ with $\mathrm{pH}$ ranging from 5.5 to 5.8 depending on the growth stages. Based on the previous suggestions on different crops and our preliminary tests on tomato, an aqueous solution of $0.25 \mathrm{mM}$ MeJA (Sigma-Aldrich, Seoul, Korea) in $0.1 \%$ ethanol solution [9,11] and 0.5 mM SA (SigmaAldrich, Seoul, Korea) in distilled water [10] were sprayed on all aerial plant parts to saturation starting from the 30th day after transplanting for 4 rounds with 7 days intervals. Harvest maturity was attained after 72 days from transplanting. Uniform-sized fruits free from any physical defects were harvested at two maturity stages (S1 and S2) (Figure 1) from the control and the treatment groups from the third cluster of each plant and the fruit at the edge of the cluster have not been included in the experiment. Sorting of S1 and S2 stages was made again in the laboratory using the color chart developed by our laboratory based on the growers' standard harvesting stages (Figure 1). The color of fruit was determined using the Hunter $\mathrm{a}^{*}$ (redness), $\mathrm{b}^{*}$ (yellowness), and $\mathrm{L}^{*}$ (brightness) values [16] by a CR400 Chroma meter (Minolta, Tokyo, Japan). Color variables were measured three times from each tomato close to the equatorial section and the average value was calculated for five sample fruit. After selection, the physicochemical data were taken immediately and samples for further analysis of important secondary metabolites that responsible for providing their bioactive profile (lycopene, $\beta$-carotene, ascorbic acid, total phenolics, and 
flavonoids) and anti-oxidant activity were sliced and freeze dried with a vacuum freeze dryer (FDT-8650, Operon, Korea) and dried samples were then ground to powder. The powdered tomato samples were filtered with $40-\mu \mathrm{m}$ mesh, packed in LDPE pouches and then stored at $-20^{\circ} \mathrm{C}$ until extraction.
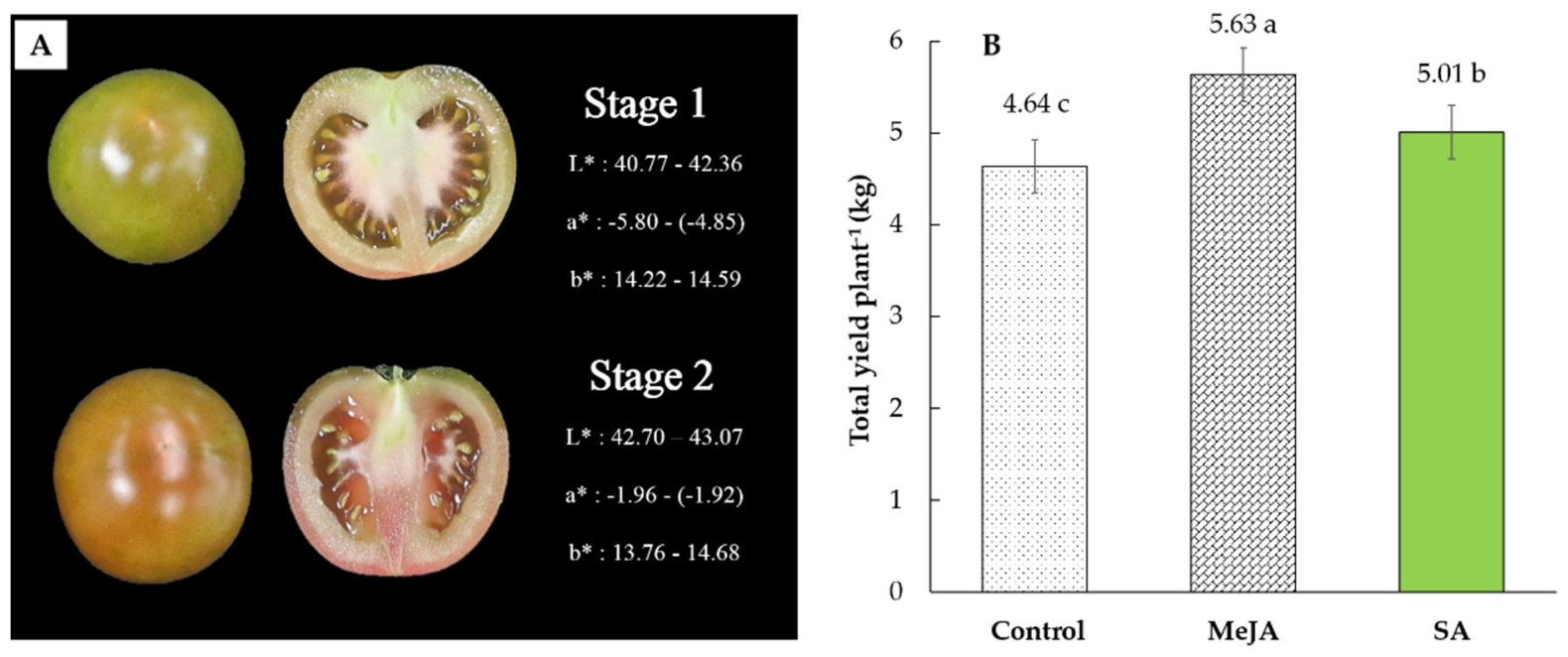

Figure 1. Harvesting stages (A) and total yield plant ${ }^{-1}(\mathbf{B})$ of 'Kumato' tomato cultivar in the control and treatment (0.25 mM MeJA and 0.5 mM SA) groups. The color of fruit was determined using the Hunter a* (redness), $b^{*}$ (yellowness), and $L^{*}$ (brightness) values.

\subsection{Crop Yield and Firmness}

Harvesting was done continuously for 2 months until the end of one growing cycle to compare production per plant in the treated groups and the control. The firmness measurements were made from five sample fruit as described by Tilahun et al. [17] at the equator of the fruit using a Rheometer (Sun Scientific Co. Ltd., Tokyo, Japan) fitted with a $3 \mathrm{~mm}$ diameter round stainless-steel probe having a flat end. The results were expressed in $\mathrm{N}$.

\subsection{Total Soluble Solids (TSS), Titratable Acidity (TA), and Brix Acid Ratio (BAR)}

TSS and TA were determined following the method described by Tilahun et al. [18]. The TSS was measured from five sample fruit at $20^{\circ} \mathrm{C}$ using digital refractometer (Atago Co. Ltd., Tokyo, Japan) and expressed in degree Brix ( ${ }^{\circ}$ Brix). TA was determined after titrating diluted tomato juice $(1 \mathrm{~mL}$ tomato juice: $19 \mathrm{~mL}$ distilled water) with $0.1 \mathrm{~N} \mathrm{NaOH}$ till pH of 8.1 using a DL22 Food and Beverage Analyzer (Mettler Toledo Ltd., Zurich, Switzerland). The citric acid (mg $100 \mathrm{~g}^{-1}$ ) of fresh tomato weight was used to express the TA result. BAR was determined by dividing the TSS with TA.

\subsection{Lycopene and $\beta$-Carotene Content}

The lycopene content was measured from three tomato samples based on the Fish et al. [19] method with some adjustments as stated by Tilahun et al. [2]. The $\beta$-carotene content was also measured from three tomato samples as described by Tilahun et al. [2] and a similar procedure used for lycopene was implemented. Freeze dried tomato samples $(1 \mathrm{~g}$ of each) were placed in to vials, to which was added $5 \mathrm{~mL}$ acetone, $5 \mathrm{~mL}$ of ethanol, and $10.0 \mathrm{~mL}$ of hexane. The vials were then centrifuged at $6000 \times g$ for $15 \mathrm{~min}$. Afterwards, $3 \mathrm{~mL}$ of deionized water was added to each vial, and the samples were shaken for another $5 \mathrm{~min}$. Vials were left at room temperature for $5 \mathrm{~min}$ without agitation to allow phase separation. Hexane layer absorbance was measured by spectrophotometer (Thermo Fisher Scientific, Waltham, MA, USA) at 503 and $448 \mathrm{~nm}$ versus blank hexane solvent for lycopene and $\beta$-carotene, respectively. The lycopene content of the samples was then expressed as mg $100 \mathrm{~g}^{-1}$ of dry weight according to the method reported by Fish et al. [19] and the 
$\beta$-carotene content was quantified and expressed as $\mathrm{mg} 100 \mathrm{~g}^{-1}$ by comparing the sample readings with the standard curve.

\subsection{Total Phenolics and Flavonoids}

Total polyphenol content was measured from three tomato samples using FolinCiocalteu colorimetric method described previously by Sokół-Łętowska et al. [20] Freeze dried tomato samples $(1 \mathrm{~g})$ were weighed in to test tubes. A total of $10 \mathrm{~mL}$ of $70 \%$ aqueous methanol was added, and vortexed. Tubes were sonicated twice for $15 \mathrm{~min}$ at room temperature $\left(22^{\circ} \mathrm{C}\right)$. The extract was centrifuged at $8000 \times g$ for $10 \mathrm{~min}$, and supernatants were used to determine the total phenolics content. The sample extracts $(0.1 \mathrm{~mL})$ were mixed with $0.2 \mathrm{~mL}$ of Folin-Ciocalteu's reagent and $2 \mathrm{~mL}$ of distilled water, and incubated at room temperature for $3 \mathrm{~min}$. Then, $1 \mathrm{~mL}$ of $20 \%(w / v) \mathrm{Na}_{2} \mathrm{CO}_{3}$ was added to the mixture and total phenolics were determined after $1 \mathrm{~h}$ of incubation. A microplate reader (Spectramax i3, Molecular Devices, Sunnyvale, CA, USA) was used to measure the absorbance of the reaction mixture at $750 \mathrm{~nm}$ against a blank sample containing the same mixture solution without the sample extract. Total phenolics content was expressed as $\mathrm{mg}$ of gallic acid equivalents (GAE) $100 \mathrm{~g}^{-1}$ dry weight of the sample.

The total flavonoid content was determined from three tomato samples using a method described by Zhishen et al. [21] with some modifications. Sample solution $(0.5 \mathrm{~mL})$ containing $10 \mathrm{mg}$ of the freeze-dried extract was mixed with $1.5 \mathrm{~mL}$ of ethanol, $0.1 \mathrm{~mL}$ of $10 \%$ aluminum nitrite solution, $0.1 \mathrm{~mL}$ of $1 \mathrm{M}$ potassium acetate solution, and $2.8 \mathrm{~mL}$ distilled water. The mixture was stirred and allowed to react for $30 \mathrm{~min}$. The absorbance was then measured at $415 \mathrm{~nm}$ using a microplate reader (Spectramax i3, Molecular Devices, Sunnyvale, CA, USA). The measurements were compared to a calibration curve of rutin and the results expressed as $\mathrm{mg}$ of rutin equivalents (RE) per $100 \mathrm{~g}^{-1}$ dry weight of the sample.

\subsection{Ascorbic Acid}

Three freeze dried tomato fruit samples $(1 \mathrm{~g})$ was mixed with $10 \mathrm{~mL}$ of $5 \%$ metaphosphoric acid and homogenized for $1 \mathrm{~min}$. The homogenized sample was centrifuged $(14,000 \times g$ for $10 \mathrm{~min})$, the liquid layer of extracts was membrane-filtered $(0.22 \mu \mathrm{m})$ and analyzed by HPLC as described by Kim et al. [22] using a ZORBAX Eclipse XDB-C18 $(4.6 \times 250 \mathrm{~mm}, 5 \mu \mathrm{m}$, Agilent, Santa Clara, CA, USA) column and detector (UV-2075, Jasco, Tokyo, Japan) at $265 \mathrm{~nm}$, with a $20 \mu \mathrm{L}$ injection of $\mathrm{MeOH}: 0.1 \mathrm{M} \mathrm{KH}_{2} \mathrm{PO}_{4}$ (1:9 ratio) at

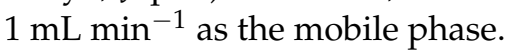

\subsection{Amino Acids and $\gamma$-Aminobutyric Acid (GABA)}

Three samples of freeze dried tomato fruit were extracted by $75 \%$ ethanol with ultrasonic extraction for $1 \mathrm{~h}$ followed by extraction at room temperature for $24 \mathrm{~h}$. Analysis was made after filtering the extract with $0.2 \mu \mathrm{L}$ filter. The amino acids content was measured by Dionex Ultimate 3000 HPLC using the method described by Henderson et al. [23].

\subsection{Antioxidant Activities}

Two extracts corresponding to the hydrophilic and hydrophobic portions from three tomato samples were prepared according to Borguini et al. [15] with some modifications from freeze dried and ground samples for the determination of antioxidant activity. To extract the hydrophilic portion, $20 \mathrm{~mL}$ of $50 \%$ methanol was added to $5 \mathrm{~g}$ of freeze dried powder, and the mixture was vortexed and incubated for $1 \mathrm{~h}$ at room temperature. Then, the mixture was centrifuged at $8000 \times g$ for $15 \mathrm{~min}$. After collecting the supernatant, $20 \mathrm{~mL}$ of $70 \%$ acetone was added to the residue. The sample was then incubated for $1 \mathrm{~h}$ followed by centrifugation at $8000 \times g$ for $15 \mathrm{~min}$. The supernatant was collected again and added to the first supernatant, and distilled water was added to the collected supernatant to reach a final volume of $50 \mathrm{~mL}$. To obtain the hydrophobic extract, $20 \mathrm{~mL}$ of ethyl ether was added to the hydrophilic extract residue. The mixture was vortexed and incubated for $1 \mathrm{~h}$ at room temperature followed by centrifugation at $8000 \times g$ for $15 \mathrm{~min}$, and the supernatant was 
collected. This procedure was repeated, and ethyl ether was added to reach a final volume of $50 \mathrm{~mL}$ supernatant.

The antioxidant activity of the hydrophilic and hydrophobic extracts were done separately and their sum was reported as the total antioxidant activity. The 2, 2-di-phenyl-1picrylhydrazyl (DPPH) radical scavenging capacity, trolox-equivalent antioxidant capacity (ABTS), and ferric reducing antioxidant power (FRAP) were measured in triplicate according to the methodology implemented previously in the laboratory and described by Baek et al. [11] The reducing power assay was performed according to the method reported by Choi et al. [24].

\subsection{Experimental Design and Statistical Analysis}

The experiment was conducted in a randomized complete block design. The data were subjected to analysis of variance (ANOVA) to determine the significance of differences between treatments at $p<0.05$ using SAS statistical software (SAS/STAT ${ }^{\circledR}$ 9.1; SAS Institute Inc., Cary, NC, USA). Heat map analysis was used to visualize the differences in amino acids content between the treatments and principal component analysis (PCA) was analyzed using XLSTA version 2015.1 (Addinsoft Inc., 244 Fifth Avenue, Suite E100, New York, NY, USA).

\section{Results and Discussion}

\subsection{Effect of Preharvest MeJA and SA Treatments on Crop Yield and Firmness}

Harvesting was done continuously from 8 May to 10 July 2020 for one growing cycle and the results for the total yield $(\mathrm{kg})$ per plant are shown in Figure 1. The data obtained from 72 plants (MeJA-treated, SA-treated, and control; 24 plants each) were used to calculate the average yield values. The average yield of MeJA-treated, SA-treated, and control tomato plants were 5.63,5.01, and $4.64 \mathrm{~kg} \mathrm{plant}^{-1}$, respectively. Thus, crop yield was significantly higher $(p<0.05)$ in preharvest MeJA-treated tomato plants, and followed by the preharvest SA-treated and control plants, respectively (Figure 1). As the treatments were applied during the active growing phase of tomato plants, higher yield from the treated plants could be attributed to the effect of MeJA and SA on alleviating biotic and abiotic stress in plants which in turn could increase net photosynthesis rate and productivity. Similar to our results, Asghari et al. [25] reported higher yield of pomegranate fruit with preharvest application of MeJA. Jahan et al. [26] also reported the enhancement of photosynthesis and water-use efficiency of tomato seedlings treated with SA.

Firmness was recorded immediately after harvest at $\mathrm{S} 1$ and $\mathrm{S} 2$ stages and the results are presented in Table 1. Generally, 'Kumato' tomato at S2 showed lower firmness than S1, irrespective of treatments. MeJA and SA treated fruit were statistically similar with the control at $\mathrm{S} 1$ maturity stage. The highest value $(12.02 \mathrm{~N})$ and the lowest value $(8.91 \mathrm{~N})$ of firmness were recorded from MeJA treated S1 and control S2, respectively. In this study, MeJA treatment was effective to maintain tomato fruit firmness at S2 compared to SA and the control (Table 1). The underlying mechanism involved in maintaining the firmness at S2 could be related to the regulation of cell wall metabolism associated genes. For instance, MeJA application in peach fruit increased the activity of phenylalanine ammonia-lyase (PAL) and peroxidase (POD) enzymes [27] that are involved in lignin biosynthesis [28,29], which could, in turn, increase fruit firmness. In addition, MeJA application could reduce the expression of polygalacturonase genes and their associated enzyme activity, and delay cell wall softening [27]. Serna-Escolano et al. [30] also reported reduction in weight loss and maintenance of firmness in lemon by preharvest MeJA and SA treatments, which were related with maintenance of cell integrity and reduction of fruit respiration rate. Firmness of tomato fruit is an important indicator for its resistance against mechanical injury during harvesting or postharvest operations [17]. Also, firmness is one of the pivotal factors that consumers use to evaluate the quality of fresh tomato fruit [31] and it depends on cultivars and maturity stages [17]. However, the results obtained in this study at both S1 and S2 stages are firmer than the lowest recommended firmness limits for home consumption 
$(1.28 \mathrm{~N})$ and at the retailers $(1.46 \mathrm{~N})$ [32]. In summary, fruit of 'Kumato' tomato at both S1 and S2 stages were very firm and resist impacts during harvesting and postharvest operations which makes them the best choice as fresh market tomatoes. Moreover, MeJA treated fruit were significantly firmer than SA treated and the control at S2 maturity stage, indicating the advantage of using preharvest MeJA treatment for maintaining firmness and improving postharvest distribution of tomato.

Table 1. Firmness, TSS, TA, and BAR of 'Kumato' tomato cultivar in the control and treatment (0.25 mM MeJA and 0.5 mM SA) groups at two maturity stages.

\begin{tabular}{ccccc}
\hline Treatments & Firmness $\mathbf{( N )}$ & TSS $\left({ }^{\circ}\right.$ Brix) & TA (mg 100 $\left.\mathbf{~ g}^{-\mathbf{1}}\right)$ & BAR \\
\hline CS1 & $11.33 \pm 0.88 \mathrm{ab}$ & $5.81 \pm 0.38 \mathrm{ab}$ & $0.80 \pm 0.02 \mathrm{a}$ & $7.20 \pm 0.84 \mathrm{c}$ \\
CS2 & $8.91 \pm 0.90 \mathrm{c}$ & $5.89 \pm 0.36 \mathrm{ab}$ & $0.66 \pm 0.07 \mathrm{c}$ & $9.05 \pm 1.12 \mathrm{a}$ \\
MeJAS1 & $12.02 \pm 1.34 \mathrm{a}$ & $5.72 \pm 0.41 \mathrm{~b}$ & $0.75 \pm 0.13 \mathrm{ab}$ & $7.60 \pm 1.38 \mathrm{c}$ \\
MeJAS2 & $10.57 \pm 1.29 \mathrm{~b}$ & $5.96 \pm 0.36 \mathrm{a}$ & $0.65 \pm 0.05 \mathrm{c}$ & $9.00 \pm 0.67 \mathrm{a}$ \\
SAS1 & $11.35 \pm 1.49 \mathrm{ab}$ & $5.97 \pm 0.45 \mathrm{a}$ & $0.73 \pm 0.11 \mathrm{~b}$ & $8.02 \pm 1.03 \mathrm{bc}$ \\
SAS2 & $9.53 \pm 1.65 \mathrm{c}$ & $5.92 \pm 0.53 \mathrm{ab}$ & $0.66 \pm 0.04 \mathrm{c}$ & $8.74 \pm 0.88 \mathrm{ab}$ \\
\hline
\end{tabular}

CS1, CS2, MeJAS1, MeJAS2, SAS1, and SAS2 represent control, preharvest MeJA and SA treatments at stages 1 and 2, respectively. Results are presented as the mean $\pm \mathrm{SD}(n=5)$ and means with different letters within the same column are significantly different at $p<0.05$.

\subsection{Effect of Preharvest MeJA and SA Treatments on TSS, TA and BAR}

The current study results have shown non-significant differences among treatments in terms of TSS, except MeJA treated fruit at S1 which revealed the lowest $\left(5.72{ }^{\circ} \mathrm{Brix}\right)$ and significantly different from MeJA treated fruit at S2. On the other hand, BAR was inversely related to TA and fruit at S2 showed higher BAR and lower TA in all treatments (Table 1). Citric acid is the major contributor to TA in tomato and low TA is assumed to be due to loss of citric acid during maturity [17]. The conversion of organic acid into sugar and their derivatives or their utilization in respiration might be the reason for the reduction in acidity as the fruit ripened $[17,33]$.The TSS $\left(5.72-5.96^{\circ} \mathrm{Brix}\right)$ in this study is higher than the range (5.16-5.20, and 5.22-5.78 ${ }^{\circ}$ Brix) reported by Tilahun et al. [33] for 'Yureka' and 'TY-megaton' tomato cultivars, respectively, implying the effect of cultivar on TSS of tomato. Similarly, the previous reports also support our current results that show an increases in TSS of tomato fruit as the maturity stage proceeds [17].

Even if the absolute TSS and TA values are considered to be determining factors, the relative proportions of TSS and TA can also be important indicator of flavor of tomato fruit. So, BAR data could be better in the estimation of flavor intensity and palatability of fruits [34]. Hence, increasing BAR could contribute to improving the flavor of tomatoes as lack of flavor is the common complaint about fresh market tomatoes. In this study, higher BAR data were recorded from S2 stage, irrespective of treatments (Table 1). Hence, preharvest MeJA and SA treatment did not affect the overall flavor intensity compared to the control.

\subsection{Effect of Preharvest MeJA and SA Treatments on Lycopene and $\beta$-Carotene Contents}

As shown in Figure 2A,B, preharvest MeJA and SA treatments increased both lycopene and $\beta$-carotene contents as compared with the control. Lycopene is one of the most active antioxidants among dietary carotenoids which is responsible for the redness of tomato fruit [2], and responsible for the biosynthesis of many carotenoids like $\beta$-carotene [35]. The present study has shown that there were significant differences $(p<0.05)$ between maturity stages and elicitors treatment in lycopene content. MeJA treated fruit exhibited the highest $\left(91.73 \mathrm{mg} 100 \mathrm{~g}^{-1}\right.$ ) lycopene content at S2 stage and was followed by SA

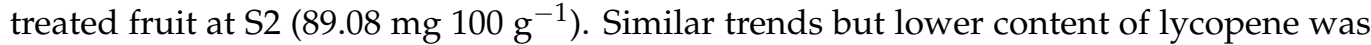
observed on fruit at $\mathrm{S} 1$ stage. The lowest $\left(52.83 \mathrm{mg} 100 \mathrm{~g}^{-1}\right)$ was recorded from control fruit at S1 stage (Figure 2A). In line with our results, Tilahun et al. [17] also reported maturity stage dependent variation of lycopene content in breaker, pink, and red stages 
of two tomato cultivars. The transformation of chloroplasts to chromoplasts results in the characteristic pigmentation of tomato fruit due to the synthesis of carotenoids [2]. As the ripe tomato fruit accumulates lycopene (red linear carotene), it also accumulates its orange cyclization pro-vitamin A product ( $\beta$-carotene) [2]. Higher lycopene content in MeJA treated fruit at both S1 and S2 strongly support the finding proposed by Liu et al. [36] that states jasmonic acid might function independently of ethylene to promote lycopene biosynthesis. The range of lycopene content (52.83-91.73 $\mathrm{mg}^{\left.100 \mathrm{~g}^{-1}\right)}$ in this study is also in agreement with previous reports. Sahin et al. [37] reported lycopene content ranging from 51.12-59.84 mg $100 \mathrm{~g}^{-1}$ from freeze dried ' $8354^{\prime}$ cultivar during their study about the influence of pretreatments and different drying methods on lycopene content of dried tomato. Similarly, Mendelová et al. [38] reported lycopene content ranging from 64.01 to $146.74 \mathrm{mg} 100 \mathrm{~g}^{-1} \mathrm{DM}$ during their evaluation of the lycopene content from eight tomato cultivars.
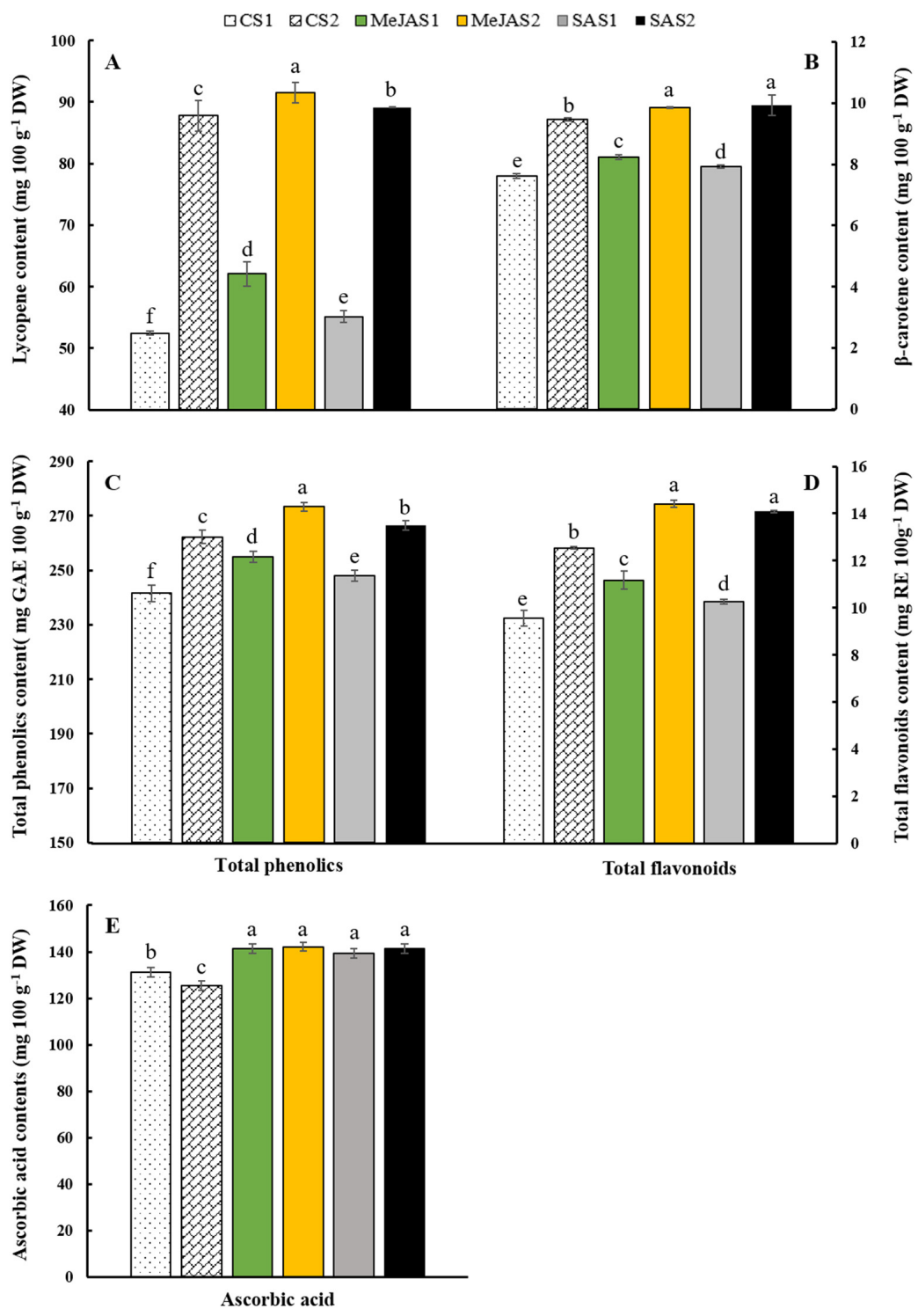

Figure 2. Lycopene (A), $\beta$-carotene (B), total phenolics (C), total flavonoids (D), and vitamin C (E) contents of 'Kumato' tomato cultivar in the control and treatment $(0.25 \mathrm{mM}$ MeJA and $0.5 \mathrm{mM}$ SA) groups at two maturity stages. The bars with different letters indicate a significant difference $(p<0.05)$ between treatments. The vertical bars represent the standard error of the means $(n=5)$. CS1, CS2, MeJAS1, MeJAS2, SAS1, and SAS2 represent control, preharvest MeJA and SA treatments at $\mathrm{S} 1$ and $\mathrm{S} 2$ maturity stages, respectively. 
In the present study, significant differences $(p<0.05)$ between maturity stages and elicitors treatment were also observed in $\beta$-carotene content and showed the same trend as lycopene (Figure 2B). Preharvest MeJA and SA treated fruit showed statistically similar and highest (9.92 and $9.85 \mathrm{mg} 100 \mathrm{~g}^{-1}$, respectively) $\beta$-carotene content at S2 while the control at S1 exhibited the lowest $\beta$-carotene content $\left(7.61 \mathrm{mg} 100 \mathrm{~g}^{-1}\right)$. Similarly, [2] reported maturity stage dependent $\beta$-carotene content from ' 244 ' tomato cultivar. The

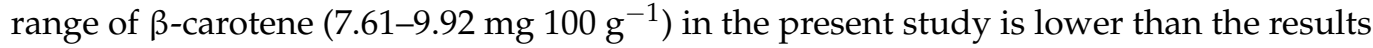
reported by Farooq et al. [39]. They obtained $\beta$-carotene contents ranging from 10.89 to

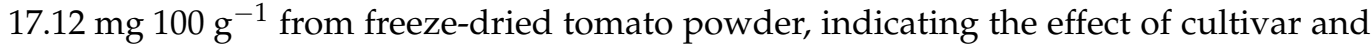
maturity stage at harvest. Taken together, the response of tomato plants to the stress caused by the preharvest MeJA and SA treatment could be the reason for the increased lycopene and $\beta$-carotene content in the treated fruit compared to the control [10].

\subsection{Effect of Preharvest MeJA and SA Treatments on Total Phenolics and Flavonoids}

Phenolic compounds are important secondary metabolites in plants that function as natural antioxidants and prevent chronic diseases related to excess free radicals by reducing oxidative stress $[40,41]$. Total phenolics correspond to the mean response of all major phenolic compounds present in fruits and vegetables [42]. Previous reports have shown that quality of fruits and vegetables could be improved by elicitors treatments by inducing accumulation of total phenolics in artichoke [43], pack choi [11] and lemon fruit [30], as a result of enhanced phenylalanine ammonia lyase (PAL) activity and reduced activity of polyphenol oxidase (PPO) [44]. Accordingly, the present results show that preharvest MeJA and SA treatments have significantly $(p<0.05)$ increased the total phenolics content at both S1 and S2 stages compared to the controls (Figure 2C). Also, fruit at S2 have shown higher total phenolics content, regardless of treatments, implying S2 could be an appropriate stage of harvesting for 'Kumato' to benefit from its higher total phenolics content. MeJA treated fruit exhibited the highest total phenolics content (273.35 mg GAE $100 \mathrm{~g}^{-1}$ ) at S2, and followed by SA treated fruit at S2 (Figure 2C). Bhandari et al. [42] have assessed twenty Korean commercial tomato cultivars and reported significantly varied

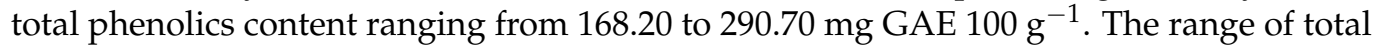
phenolics content in the present study (241.58-273.35 mg GAE $100 \mathrm{~g}^{-1}$ ) is higher than most cultivars studied by Bhandari et al. [42].

Flavonoids are the main component of total phenolics and possess strong antioxidant activity that significantly contributes to the health benefits [45]. Tomatoes have been recognized as an important source of dietary flavonoids due to a high consumption worldwide [46]. Hence, efforts have been made to elevate flavonoids concentration in different tomato cultivars [46]. In the present study, preharvest MeJA and SA treatments have significantly $(p<0.05)$ increased the total flavonoids content at both S1 and S2 stages compared to the controls (Figure 2D). Similar to total phenolics, fruit at S2 have shown higher total flavonoids content, regardless of treatments, implying S2 could be an appropriate stage of harvesting for 'Kumato' to benefit from its higher total flavonoids content. Previous results of flavonoids ranging from 197-211 mg RE $100 \mathrm{~g}^{-1} \mathrm{DM}$ were also reported by Toor and Savage [47] for tomatoes of three cultivars during their investigation of the effect of semidrying on antioxidant components of tomatoes. Taken together, all the treatments in the present study have shown higher contents of total phenolics and flavonoids as compared to the previous reports, suggesting superior quality and higher nutritional value of 'Kumato' tomato. Moreover, MeJA was more effective than SA on improving total phenolics and flavonoids of 'Kumato' tomato as indicated in Figure 3C,D. The improvement in total phenolics and flavonoids content of preharvest MeJA and SA treated fruit could be due to the regulation of various physiological and metabolic processes [10], which in turn affect the nutritional quality of crops. 


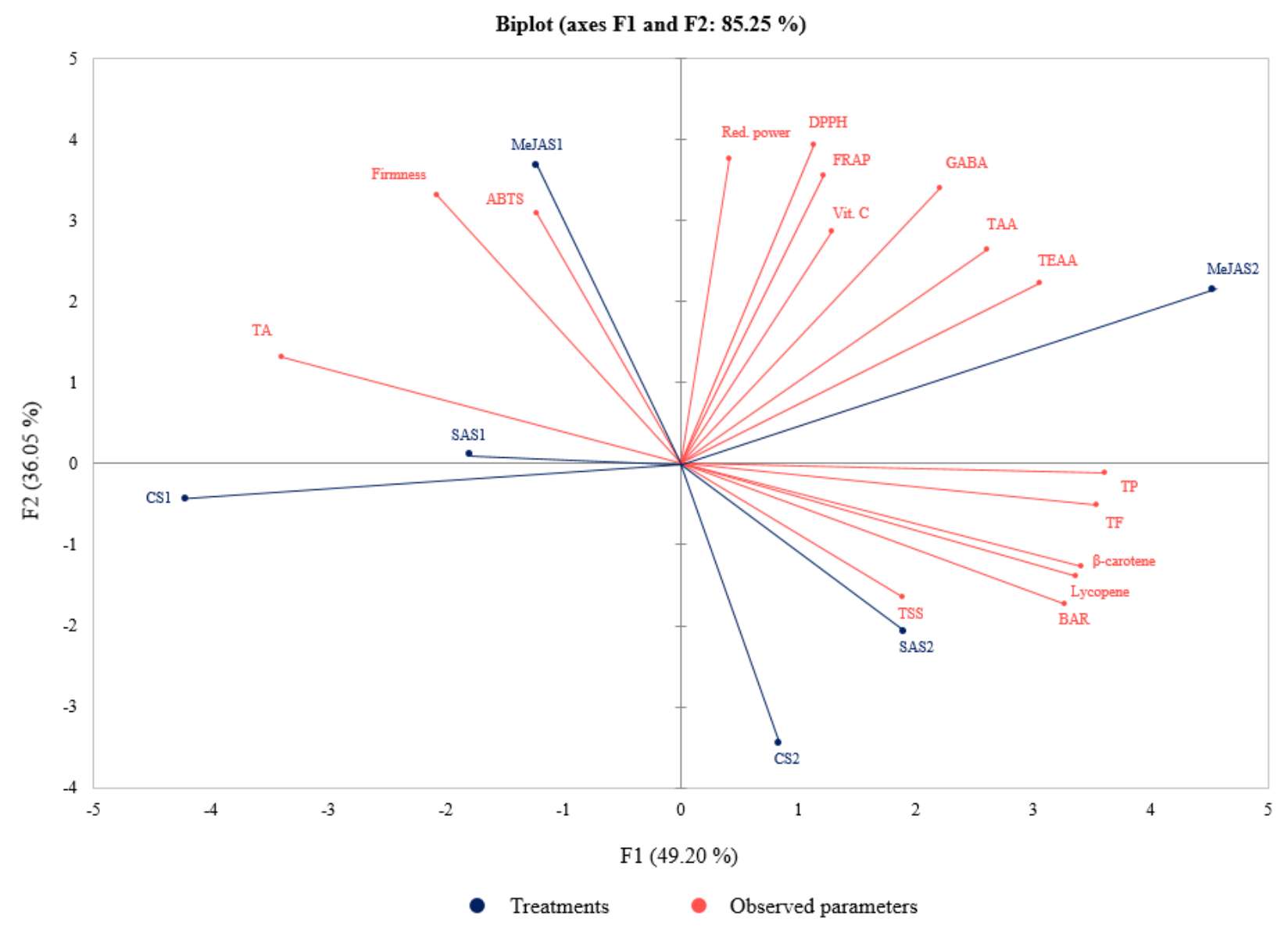

Figure 3. Biplot of the principal component analysis of the observed parameters of 'Kumato' tomato cultivar in the control and treatment (0.25 mM MeJA and 0.5 mM SA) groups at two maturity stages. CS1, CS2, MeJAS1, MeJAS2, SAS1, and SAS2 represent control, preharvest MeJA and SA treatments at S1 and S2 maturity stages, respectively. TSS, TA, BAR, TP, TF, TAA, TEAA, GABA, Vit. C, DPPH, ABTS, FRAP and Red. power represent total soluble solids, titratable Acidity, Brix acid ratio, total phenolics, total flavonoids, total amino acids, total essential amino acids, $\gamma$-aminobutyric acid, vitamin $C$, 2, 2-di-phenyl-1-picrylhydrazyl radical scavenging capacity, Trolox-equivalent antioxidant capacity, and ferric-reducing antioxidant power, and reducing power, respectively.

\subsection{Effect of Preharvest MeJA and SA Treatments on Ascorbic Acid Content}

Tomato fruit contains ascorbic acid (vitamin C) $[4,40]$ which is easily absorbed by the body. It has a lot of health benefits like preventing low-density lipoprotein oxidation, fighting scurvy, maintain collagen and ameliorate neurodegenerative disease Yahia et al. [48]. Preharvest MeJA and SA treatments have significantly $(p<0.05)$ increased the vitamin $\mathrm{C}$ content at both S1 and S2 stages compared to the control. The lowest ascorbic acid content (125.98 mg $100 \mathrm{~g}^{-1}$ ) was obtained from the control at S2 (Figure 2E). Similarly, Tilahun et al. [17] reported the decreasing trend of ascorbic acid in 'TY Megaton' and 'Yureka' tomato cultivars as maturity stages proceed from breaker to red. However,

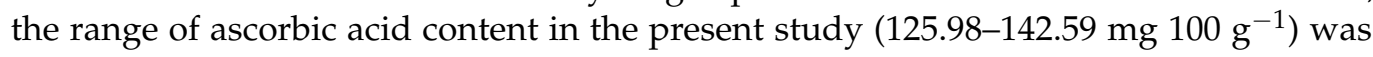
higher than previous reports, indicating higher ascorbic acid content of 'Kumato' tomato. Farooq et al. [39] reported ascorbic acid contents ranging from 33.53 to $42.19 \mathrm{mg} 100 \mathrm{~g}^{-1}$ from freeze-dried tomato powder. The improvement in ascorbic acid content of preharvest MeJA and SA treated fruit could be due to the regulation of various physiological and metabolic processes [10], which in turn affect the nutritional quality of crops. 


\subsection{Effect of Preharvest MeJA and SA Treatments on Contents of Free Amino Acids}

The content of total free amino acids was significantly $(p<0.05)$ different among the treatments. From all treatments, the total free amino acid content of MeJA treated tomato was the highest at S2 $\left(68.10 \mathrm{~g} \mathrm{~kg}^{-1}\right)$ followed by MeJA treated tomato at $S 1\left(47.51 \mathrm{~g} \mathrm{~kg}^{-1}\right)$, SA treated at S2 $\left(43.04 \mathrm{~g} \mathrm{~kg}^{-1}\right)$, and control at S2 $\left(38.44 \mathrm{~g} \mathrm{~kg}^{-1}\right)$, respectively (Table 2 and Figure S1). In agreement with the current results, Junbae Ahn [49] tested 'Rafito', 'Momotaro', and 'Medison' tomato cultivars and reported total free amino acid content ranging from 38.10 to $45.94 \mathrm{~g} \mathrm{~kg}^{-1}$ dry weight. In this study, glutamine was the most abundant free amino acid in all treatments, ranging from $24.61 \mathrm{~g} \mathrm{~kg}^{-1}$ in preharvest MeJA treated fruit at S2 to $10.98 \mathrm{~g} \mathrm{~kg}^{-1}$ in control at S1. Glutamic acid was the second most abundant free amino acid in all treatments and the contents ranged from $16.84 \mathrm{~g} \mathrm{~kg}^{-1}$ in preharvest MeJA treated fruit at S2 to $5.72 \mathrm{~g} \mathrm{~kg}^{-1}$ in SA treated at S1. Sorrequieta et al. [50] also reported glutamine and glutamate as the most abundant free amino acid during ripening of tomato fruit. The relative proportions of GABA, aspartic acid, serine, and asparagine were also higher than the other amino acids in all treatments (Table 2 and Figure S1). Similarly, Pratta et al. [51] and Boggio et al. [52] also obtained higher relative content of glutamine, glutamate, GABA, asparagine, serine, and aspartic acid in various cultivars of tomatoes at different maturity stages.

The levels of nine essential amino acids (histidine, isoleucine, leucine, lysine, methionine, phenylalanine, threonine, tryptophan, and valine) can be used to measure the quality of the protein in a foodstuff [49]. The results of this study also showed a significant difference $(p<0.05)$ among treatments in the contents of essential amino acids. Of the total free amino acids, the essential amino acid content ranged from $3.52 \mathrm{~g} \mathrm{~kg}^{-1}$ in control at S1 to $5.98 \mathrm{~g} \mathrm{~kg}^{-1}$ in preharvest MeJA treated fruit at S2 (Table 2). Preharvest MeJA treated fruit at $\mathrm{S} 1$ showed the second most abundant essential amino acids followed by the control and preharvest SA treated fruit at S2, respectively. Hence, MeJA was more effective than SA on improving the contents of essential amino acids at both S1 and S2. A high level of GABA was found to accumulate in tomato fruit before the breaker stage and catabolized rapidly thereafter [6]. Sorrequieta et al. [50] also emphasized that GABA contents reduced significantly during the ripening transition. However, in the present study, preharvest MeJA treated 'Kumato' tomato significantly dominates the other treatments in terms of GABA content at S2 (Table 2 and Figure S2), and followed by preharvest MeJA treated at S1. Similarly, preharvest SA treatment improved GABA content at both S1 and S2 as compared to the control fruit. Hence, preharvest MeJA and SA treatment could assist in improving the nutritional quality of 'Kumato' tomato as the treatments maintain GABA at both $S 1$ and S2 stages. In addition to the preharvest MeJA and SA treatments, nature of the cultivar could be one of the reasons for maintaining GABA at S2 stage (Figure 1). Ahn [47] evaluated three tomato cultivars at full maturity and observed significant differences in GABA content among the cultivars, and reported 8.68, 7.60, and $6.67 \mathrm{~g} \mathrm{~kg}^{-1}$ DW GABA contents for 'Rafito', 'Momotaro TY', and 'Medison', respectively. In this study, the highest GABA content ( 8.07 and $6.63 \mathrm{~g} \mathrm{~kg}^{-1}$ ) were recorded from preharvest MeJA treated tomato at S2 and S1 stages, respectively, while the lowest (3.90 and $3.69 \mathrm{~g} \mathrm{~kg}^{-1}$ ) were recorded from control at S1 and S2 stages, respectively (Table 2 and Figure S2). Preharvest SA treatment lies in between and revealed 4.71 and $4.89 \mathrm{~g} \mathrm{~kg}^{-1}$ GABA contents at S1 and S2 stages, respectively. Therefore, MeJA was more effective than SA on improving GABA content of 'Kumato' tomato. 
Table 2. Free amino acids content in the preharvest MeJA and SA treated and control fruit of 'Kumato' tomato cultivar at two maturity stages.

\begin{tabular}{|c|c|c|c|c|c|c|c|c|c|c|c|c|}
\hline \multirow{2}{*}{ Amino Acids } & \multicolumn{2}{|c|}{ CS1 } & \multicolumn{2}{|c|}{ CS2 } & \multicolumn{2}{|c|}{ MeJAS1 } & \multicolumn{2}{|c|}{ MeJAS2 } & \multicolumn{2}{|c|}{ SAS1 } & \multicolumn{2}{|c|}{ SAS2 } \\
\hline & $\mathrm{mg} \mathrm{kg}^{-1}$ & $\%$ & $\mathrm{mg} \mathrm{kg}^{-1}$ & $\%$ & $\mathrm{mg} \mathrm{kg}^{-1}$ & $\%$ & $\mathrm{mg} \mathrm{kg}^{-1}$ & $\%$ & $\mathrm{mg} \mathrm{kg}^{-1}$ & $\%$ & $\mathrm{mg} \mathrm{kg}^{-1}$ & $\%$ \\
\hline Aspartic acid & $1825.59 \mathrm{c}$ & 5.91 & $2594.13 \mathrm{~b}$ & 6.75 & $2466.38 \mathrm{~b}$ & 5.19 & $4125.27 \mathrm{a}$ & 6.06 & $1800.91 \mathrm{c}$ & 5.15 & $2632.83 \mathrm{~b}$ & 6.12 \\
\hline Glutamic acid & $5999.00 \mathrm{~d}$ & 19.41 & $10,765.44 \mathrm{~b}$ & 28.00 & $8680.55 c$ & 18.27 & $16,839.05 \mathrm{a}$ & 24.73 & $5720.51 \mathrm{~d}$ & 16.37 & $10,660.70 \mathrm{~b}$ & 24.77 \\
\hline Asparagine & $1371.58 \mathrm{e}$ & 4.44 & $1602.25 \mathrm{~d}$ & 4.17 & $2270.39 \mathrm{~b}$ & 4.78 & $3130.00 \mathrm{a}$ & 4.60 & $1858.46 \mathrm{c}$ & 5.32 & 2079.48 b & 4.83 \\
\hline Serine & $2267.48 \mathrm{c}$ & 7.34 & $2323.83 \mathrm{c}$ & 6.05 & $2779.89 \mathrm{~b}$ & 5.85 & 3448.83 a & 5.06 & $2166.29 \mathrm{c}$ & 6.20 & $2218.57 \mathrm{c}$ & 5.15 \\
\hline Glutamine & $10,980.84 \mathrm{~d}$ & 35.53 & $12,448.05 \mathrm{~d}$ & 32.38 & $18,627.28 \mathrm{~b}$ & 39.21 & $24,606.23 \mathrm{a}$ & 36.14 & $14,470.59 \mathrm{c}$ & 41.41 & $15,803.62$ c & 36.71 \\
\hline Histidine (EAA) & $326.77 \mathrm{c}$ & 1.06 & $426.96 \mathrm{~b}$ & 1.11 & $399.39 \mathrm{~b}$ & 0.84 & $550.79 \mathrm{a}$ & 0.81 & 307.96 c & 0.88 & $440.25 \mathrm{~b}$ & 1.02 \\
\hline Glycine & $134.74 \mathrm{c}$ & 0.44 & $144.08 \mathrm{c}$ & 0.37 & $164.93 \mathrm{~b}$ & 0.35 & $202.93 \mathrm{a}$ & 0.30 & $126.30 \mathrm{c}$ & 0.36 & $135.23 \mathrm{c}$ & 0.31 \\
\hline Threonine (EAA) & $952.08 \mathrm{~cd}$ & 3.08 & $1080.18 \mathrm{~b}$ & 2.81 & $1021.90 \mathrm{bc}$ & 2.15 & $1398.58 \mathrm{a}$ & 2.05 & $858.75 \mathrm{~d}$ & 2.46 & $939.56 \mathrm{~cd}$ & 2.18 \\
\hline Arginine & $288.71 \mathrm{~cd}$ & 0.34 & $360.56 \mathrm{~b}$ & 0.34 & $353.24 \mathrm{~b}$ & 0.34 & $550.16 \mathrm{a}$ & 0.34 & $250.58 \mathrm{~d}$ & 0.34 & $329.97 \mathrm{bc}$ & 0.34 \\
\hline Citrulline & $30.05 \mathrm{~d}$ & 0.10 & $25.10 \mathrm{~d}$ & 0.07 & $65.02 \mathrm{~b}$ & 0.14 & $76.67 \mathrm{a}$ & 0.11 & $53.57 \mathrm{c}$ & 0.15 & $46.95 \mathrm{c}$ & 0.11 \\
\hline Alanine & $239.28 \mathrm{c}$ & 0.77 & $200.77 \mathrm{~d}$ & 0.52 & $300.54 \mathrm{~b}$ & 0.63 & $362.37 \mathrm{a}$ & 0.53 & $221.88 \mathrm{~cd}$ & 0.63 & $219.72 \mathrm{~cd}$ & 0.51 \\
\hline GABA & $3903.29 \mathrm{~d}$ & 12.63 & $3694.15 \mathrm{~d}$ & 9.61 & $6627.36 \mathrm{~b}$ & 13.95 & $8070.42 \mathrm{a}$ & 11.85 & $4710.94 \mathrm{c}$ & 13.48 & $4893.20 \mathrm{c}$ & 11.37 \\
\hline Tyrosine & $152.71 \mathrm{c}$ & 0.49 & 145.65 c & 0.38 & $235.14 \mathrm{~b}$ & 0.49 & $286.23 \mathrm{a}$ & 0.42 & $139.70 \mathrm{c}$ & 0.40 & $142.60 \mathrm{c}$ & 0.33 \\
\hline Valine (EAA) & $370.07 \mathrm{~cd}$ & 1.20 & $406.47 \mathrm{bc}$ & 1.06 & $438.58 \mathrm{~b}$ & 0.92 & $554.34 \mathrm{a}$ & 0.81 & $359.99 \mathrm{~d}$ & 1.03 & $374.56 \mathrm{~cd}$ & 0.87 \\
\hline Methionine (EAA) & $33.64 \mathrm{c}$ & 0.11 & $45.92 \mathrm{bc}$ & 0.12 & $45.69 \mathrm{bc}$ & 0.10 & $73.45 \mathrm{a}$ & 0.11 & $33.18 \mathrm{c}$ & 0.09 & $50.36 \mathrm{~b}$ & 0.12 \\
\hline Tryptophane (EAA) & $87.61 \mathrm{~d}$ & 0.28 & $97.91 \mathrm{~d}$ & 0.25 & $204.35 \mathrm{~b}$ & 0.43 & $265.92 \mathrm{a}$ & 0.39 & $127.76 \mathrm{c}$ & 0.37 & $147.58 \mathrm{c}$ & 0.34 \\
\hline Phenylalanine (EAA) & $751.41 \mathrm{c}$ & 2.43 & $737.16 \mathrm{c}$ & 1.92 & $1281.04 \mathrm{~b}$ & 2.70 & 1532.55 a & 2.25 & $670.30 \mathrm{c}$ & 1.92 & $769.83 \mathrm{c}$ & 1.79 \\
\hline Leucine (EAA) & $293.61 \mathrm{c}$ & 0.95 & $319.85 \mathrm{bc}$ & 0.83 & $354.15 \mathrm{~b}$ & 0.75 & 449.93 a & 0.66 & $267.60 \mathrm{c}$ & 0.77 & 274.02 c & 0.64 \\
\hline Lysine (EAA) & 299.05 c & 0.97 & $386.07 \mathrm{~b}$ & 1.00 & $390.60 \mathrm{~b}$ & 0.82 & 496.85 a & 0.73 & $248.84 \mathrm{~d}$ & 0.71 & $281.22 \mathrm{~cd}$ & 0.65 \\
\hline Proline & 197.99 c & 0.64 & $222.77 \mathrm{c}$ & 0.58 & $305.38 \mathrm{~b}$ & 0.64 & 415.18 a & 0.61 & $176.44 \mathrm{c}$ & 0.50 & 208.67 c & 0.48 \\
\hline Total EAA & $3518.87 \mathrm{f}$ & 11.38 & $3915.03 c$ & 10.18 & $4635.02 \mathrm{~b}$ & 9.76 & $5978.30 \mathrm{a}$ & 8.78 & $3247.72 \mathrm{e}$ & 9.29 & $3672.61 \mathrm{~d}$ & 8.53 \\
\hline Total & $30,910.13$ e & & $38,441.80 \mathrm{~cd}$ & & $47,511.12 \mathrm{~b}$ & & $68,091.61 \mathrm{a}$ & & $34,943.89$ de & & $43,044.13$ bc & \\
\hline
\end{tabular}

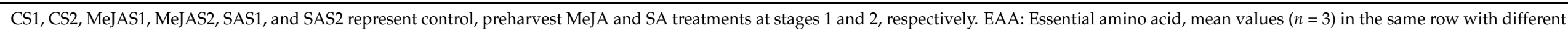

letters are significantly different at $p<0.05$. 


\subsection{Effect of Preharvest MeJA and SA Treatments of Antioxidant Activity}

The results of the present study showed the significant $(p<0.05)$ differences in antioxidant activities in response to preharvest MeJA and SA treatments at both S1 and S2 stages (Table 3). Nutritional quality of tomato fruit is strongly dependent on the antioxidants [45]. The DPPH scavenging capacity of the treatments in the present study was significantly different ranging from $88.08 \%$ in preharvest MeJA treated fruit at S2 to $79.73 \%$ in control fruit at S2 (Table 3). Similarly, FRAP and reducing power absorbance values exhibited significantly higher values in preharvest MeJA treated fruit at both S1 and S2 stages as compared to preharvest SA treated and the control. From the antioxidant determination methods used in this study, ABTS showed statistically similar reducing power except preharvest MeJA treated fruit at S1 which exhibited statistically higher ABTS reducing capacity. Generally, the highest scavenging capacity was recorded from preharvest MeJA-treated 'Kumato' tomato, followed by preharvest SA treated and the control, respectively, at both S1 and S2 stages (Table 3).

Table 3. The DPPH (2,2-di-phenyl-1-picrylhydrazyl) radical scavenging capacity, Trolox-equivalent antioxidant capacity (ABTS), ferric-reducing antioxidant power (FRAP), and reducing power of 'Kumato' tomato cultivar in the control and treatment ( $0.25 \mathrm{mM}$ MeJA and $0.5 \mathrm{mM} \mathrm{SA})$ groups at two maturity stages.

\begin{tabular}{ccccc}
\hline Treatments & DPPH (\%) & ABTS (\%) & $\begin{array}{c}\text { FRAP } \\
\text { (Absorbance) }\end{array}$ & $\begin{array}{c}\text { Reducing } \\
\text { Power } \\
\text { (Absorbance) }\end{array}$ \\
\hline CS1 & $80.88 \pm 1.87 \mathrm{c}$ & $21.78 \pm 3.72 \mathrm{ab}$ & $0.044 \pm 0.004 \mathrm{~b}$ & $0.281 \pm 0.000 \mathrm{~d}$ \\
CS2 & $79.73 \pm 1.05 \mathrm{c}$ & $19.95 \pm 2.43 \mathrm{~b}$ & $0.046 \pm 0.008 \mathrm{~b}$ & $0.272 \pm 0.000 \mathrm{e}$ \\
MeJAS1 & $86.78 \pm 1.19 \mathrm{a}$ & $23.71 \pm 0.92 \mathrm{a}$ & $0.074 \pm 0.007 \mathrm{a}$ & $0.297 \pm 0.001 \mathrm{a}$ \\
MeJAS2 & $88.08 \pm 1.43 \mathrm{a}$ & $20.81 \pm 1.31 \mathrm{~b}$ & $0.085 \pm 0.023 \mathrm{a}$ & $0.291 \pm 0.001 \mathrm{~b}$ \\
SAS1 & $83.62 \pm 1.49 \mathrm{~b}$ & $20.11 \pm 1.17 \mathrm{~b}$ & $0.063 \pm 0.023 \mathrm{ab}$ & $0.289 \pm 0.003 \mathrm{bc}$ \\
SAS2 & $79.77 \pm 1.12 \mathrm{c}$ & $20.76 \pm 0.97 \mathrm{~b}$ & $0.035 \pm 0.001 \mathrm{~b}$ & $0.287 \pm 0.003 \mathrm{c}$ \\
\hline
\end{tabular}

Results are presented as the mean \pm SD from triplicate independent values. Means with different letters within the same column are significantly different at $p<0.05$. CS1, CS2, MeJAS1, MeJAS2, SAS1, and SAS2 represent control, preharvest MeJA and SA treatments at S1 and S2 maturity stages, respectively. All data were detected at $10 \mathrm{mg} \mathrm{mL}^{-1}$ methanol extracts of tomatoes.

\subsection{Principal Component Analysis}

Principal component analysis explains the difference between the treatments and the observed parameters that largely affect the spatial distribution, and the correlation of the observed parameters [11]. The PCA of the observed parameters in this study is presented in Figure 3. TSS, TA, BAR, contents of lycopene, $\beta$-carotene, total phenolics, flavonoids, vitamin $C$, total amino acids, total essential amino acids, GABA, and antioxidant activities were used as variables to perform the PCA. The treatments were separated based on the above parameters, and factor 1 (F1) and factor 2 (F2) comprised about $85.25 \%$ of the total variance. $\mathrm{F} 1$ showed about $49.20 \%$ of the total variance and positively correlated to the total amino acids, total essential amino acids, GABA, vitamin C, the antioxidant activities (FRAP, $\mathrm{DPPH}$, and reducing power), total phenolics and flavonoids, lycopene and $\beta$-carotene, BAR and TSS. As shown in Figure 3, the above parameters were also higher at S2 in preharvest MeJA-treated 'Kumato' tomato fruit followed by preharvest SA-treated and the control, respectively. The F2 accounted for about $36.05 \%$ of the total variance and mainly represented variances in firmness, TA and ABTS. The parameters represented in F2 were also higher in preharvest MeJA-treated 'Kumato' tomato fruit at S1. Taken together, the preharvest MeJA treatment showed a great impact on the measured parameters, mainly at S2 (Figure 3). 


\section{Conclusions}

The current study indicated the improvement of the yield and quality of tomato fruit through the preharvest MeJA and SA treatment. From the results, preharvest MeJA treatment was more effective than SA on improving secondary bioactive substances, essential amino acids, GABA, and antioxidant activity of 'Kumato' tomato. Further investigation on additional cultivars could be necessary to recommend the use of preharvest MeJA treatment as a tool for responding to the growing demand of consumers for high quality tomato for healthy eating.

Supplementary Materials: The following are available online at https://www.mdpi.com/article/ 10.3390/agronomy11112293/s1, Figure S1. Heat map of amino acids in the preharvest MeJA and SA treated and control fruit of 'Kumato' tomato cultivar at two maturity stages. Figure S2. GABA content of 'Kumato' tomato cultivar in the control and treatment (0.25 mM MeJA and 0.5 mM SA) groups at two maturity stages.

Author Contributions: Conceptualization and Methodology, M.W.B., S.T. and C.S.J.; data curation, M.W.B. and L.Y.J.; software and formal analysis, S.T. and H.R.C.; resources, C.S.J.; original draft preparation, M.W.B., S.T. and H.R.C.; review and editing, S.T., H.-M.K. and O.-H.L.; supervision, C.S.J., S.T. and O.-H.L.; project administration, H.R.C.; and funding acquisition, C.S.J. All authors have read and agreed to the published version of the manuscript.

Funding: Financial support from scientific and technological support program through the National Research Foundation of Korea (NRF) funded by the Ministry of Education (NRF-2019K1A3A9A0100002412) is gratefully acknowledged.

Institutional Review Board Statement: Not applicable.

Informed Consent Statement: Not applicable.

Data Availability Statement: All data sets are available upon reasonable request from the corresponding author.

Conflicts of Interest: The authors declare no conflict of interest.

\section{References}

1. FAOSTAT Food \& Agriculture Organization of the United Nations Statistics Division. Available online: http://faostat3.fao.org/ home/index.html (accessed on 10 December 2020).

2. Tilahun, S.; Seo, M.H.; Hwang, I.G.; Kim, S.H.; Choi, H.R.; Jeong, C.S. Prediction of lycopene and $\beta$-carotene in tomatoes by portable chroma-meter and VIS/NIR spectra. Postharvest Biol. Technol. 2018, 136, 50-56. [CrossRef]

3. Stahl, W.; Sies, H. Antioxidant activity of carotenoids. Mol. Asp. Med. 2003, 24, 345-351. [CrossRef]

4. Periago, M.J.; García-Alonso, J.; Jacob, K.; Olivares, A.B.; Bernal, M.J.; Iniesta, M.D.; Martínez, C.; Ros, G. Bioactive compounds, folates and antioxidant properties of tomatoes (Lycopersicum esculentum) during vine ripening. Int. J. Food Sci. Nutr. 2009, 60, 694-708. [CrossRef] [PubMed]

5. Periago, M.J.; Martínez-Valverde, I.; Chesson, A.; Provan, G. Phenolic compounds, lycopene and antioxidant activity in commercial varieties of tomato (Lycopersicum esculentum). J. Sci. Food Agric. 2002, 82, 323-330. [CrossRef]

6. Akihiro, T.; Koike, S.; Tani, R.; Tominaga, T.; Watanabe, S.; Iijima, Y.; Aoki, K.; Shibata, D.; Ashihara, H.; Matsukura, C. Biochemical mechanism on GABA accumulation during fruit development in tomato. Plant Cell Physiol. 2008, 49, 1378-1389. [CrossRef] [PubMed]

7. Owens, D.F.; Kriegstein, A.R. Is there more to GABA than synaptic inhibition? Nat. Rev. Neurosci. 2002, 3, 715-727. [CrossRef]

8. Takayama, M.; Ezura, H. How and why does tomato accumulate a large amount of GABA in the fruit? Front. Plant Sci. 2015, 6, 612. [CrossRef]

9. Ku, K.M.; Juvik, J.A. Environmental stress and methyl jasmonate-mediated changes in flavonoid concentrations and antioxidant activity in broccoli florets and kale leaf tissues. HortScience 2013, 48, 996-1002. [CrossRef]

10. Sariñana-Aldaco, O.; Sánchez-Chávez, E.; Troyo-Diéguez, E.; Tapia-Vargas, L.M.; Díaz-Pérez, J.C.; Preciado-Rangel, P. Foliar aspersion of salicylic acid improves nutraceutical quality and fruit yield in Tomato. Agriculture 2020, 10, 482. [CrossRef]

11. Baek, M.W.; Choi, H.R.; Solomon, T.; Jeong, C.S.; Lee, O.-H.; Tilahun, S. Preharvest Methyl Jasmonate Treatment Increased the Antioxidant Activity and Glucosinolate Contents of Hydroponically Grown Pak Choi. Antioxidants 2021, 10, 131. [CrossRef] [PubMed]

12. Bradbury, S. Methyl Jasmonate; Exemption from the Requirement of a Tolerance; Federal Register. A Rule by the Environmental Protection Agency (EPA). Fed. Regist. 2013, 78, 13-19. 
13. Koo, Y.M.; Heo, A.Y.; Choi, H.W. Salicylic acid as a safe plant protector and growth regulator. Plant Pathol. J. 2020, 36, 1-10. [CrossRef] [PubMed]

14. Ezzat, A.; Ammar, A.; Szabó, Z.; Nyéki, J.; Holb, I.J. Postharvest Treatments with Methyl Jasmonate and Salicylic Acid for Maintaining Physico-Chemical Characteristics and Sensory Quality Properties of Apricot Fruit during Cold Storage and Shelf-Life. Pol. J. Food Nutr. Sci. 2017, 67, 159-166. [CrossRef]

15. Borguini, R.G.; Helena, D.; Bastos, M.; Moita-Neto, J.M.; Capasso, F.S.; Aparecida, E.; Da, F.; Torres, S. Antioxidant Potential of Tomatoes Cultivated in Organic and Conventional Systems. Braz. Arch. Biol. Technol. 2013, 56456, 521-529. [CrossRef]

16. McGuire, R.G. Reporting of Objective Color Measurements. HortScience 1992, 27, 1254-1255. [CrossRef]

17. Tilahun, S.; Park, D.S.; Solomon, T.; Choi, H.R.; Jeong, C.S. Maturity stages affect nutritional quality and storability of tomato cultivars. CYTA-J. Food 2019, 17, 87-95. [CrossRef]

18. Tilahun, S.; Park, D.S.; Taye, A.M.; Jeong, C.S. Effect of ripening conditions on the physicochemical and antioxidant properties of tomato (Lycopersicon esculentum Mill.). Food Sci. Biotechnol. 2017, 26, 473-479. [CrossRef]

19. Fish, W.W.; Perkins-Veazie, P.; Collins, J.K. A quantitative assay for lycopene that utilizes reduced volumes of organic solvents. J. Food Compos. Anal. 2002, 15, 309-317. [CrossRef]

20. Sokół-Łetowska, A.; Oszmiański, J.; Wojdyło, A. Antioxidant activity of the phenolic compounds of hawthorn, pine and skullcap. Food Chem. 2007, 103, 853-859. [CrossRef]

21. Zhishen, J.; Mengcheng, T.; Jianming, W. The determination of flavonoid contents in mulberry and their scavenging effects on superoxide radicals. Food Chem. 1999, 64, 555-559. [CrossRef]

22. Kim, H.S.; Jung, J.Y.; Kim, H.K.; Ku, K.M.; Suh, J.K.; Park, Y.; Kang, Y.H. Influences of Meteorological Conditions of Harvest Time on Water-Soluble Vitamin Contents and Quality Attributes of Oriental Melon. Prot. Hortic. Plant Fact. 2011, $20,290-296$.

23. Henderson, J.W.; Ricker, R.D.; Bidlingmeyer, B.A.; Woodward, C. Rapid, Accurate, Sensitive, and Reproducible HPLC Analysis of Amino Acids. Amino Acids 2000, 1100, 1-10.

24. Choi, Y.E.; Choi, S.I.; Han, X.; Men, X.; Jang, G.W.; Kwon, H.Y.; Kang, S.R.; Han, J.S.; Lee, O.H. Radical scavenging-linked anti-adipogenic activity of aster scaber ethanolic extract and its bioactive compound. Antioxidants 2020, 9, 1290. [CrossRef]

25. Asghari, M.; Merrikhi, M.; Kavoosi, B. Methyl Jasmonate Foliar Spray Substantially Enhances the Productivity, Quality and Phytochemical Contents of Pomegranate Fruit. J. Plant Growth Regul. 2020, 39, 1153-1161. [CrossRef]

26. Shah Jahan, M.; Wang, Y.; Shu, S.; Zhong, M.; Chen, Z.; Wu, J.; Sun, J.; Guo, S. Exogenous salicylic acid increases the heat tolerance in Tomato (Solanum lycopersicum L) by enhancing photosynthesis efficiency and improving antioxidant defense system through scavenging of reactive oxygen species. Sci. Hortic. 2019, 247, 421-429. [CrossRef]

27. Yao, H.J.; Tian, S.P. Effects of a biocontrol agent and methyl jasmonate on postharvest diseases of peach fruit and the possible mechanisms involved. J. Appl. Microbiol. 2005, 98, 941-950. [CrossRef] [PubMed]

28. Tanaka, Y.; Matsuoka, M.; Yamanoto, N.; Ohashi, Y.; Kano-Murakami, Y.; Ozeki, Y. Structure and Characterization of a cDNA Clone for Phenylalanine Ammonia-Lyase from Cut-Injured Roots of Sweet Potato. Plant Physiol. 1989, 90, 1403-1407. [CrossRef] [PubMed]

29. García-Ulloa, A.; Sanjurjo, L.; Cimini, S.; Encina, A.; Martínez-Rubio, R.; Bouza, R.; Barral, L.; Estévez-Pérez, G.; Novo-Uzal, E.; De Gara, L. Overexpression of ZePrx in Nicotiana tabacum Affects Lignin Biosynthesis without Altering Redox Homeostasis. Front. Plant Sci. 2020, 11, 900. [CrossRef]

30. Serna-Escolano, V.; Martínez-Romero, D.; Giménez, M.J.; Serrano, M.; García-Martínez, S.; Valero, D.; Valverde, J.M.; Zapata, P.J. Enhancing antioxidant systems by preharvest treatments with methyl jasmonate and salicylic acid leads to maintain lemon quality during cold storage. Food Chem. 2021, 338, 128044. [CrossRef]

31. Wu, T.; Abbott, J.A. Firmness and force relaxation characteristics of tomatoes stored intact or as slices. Postharvest Biol. Technol. 2002, 24, 59-68. [CrossRef]

32. Batu, A. Determination of acceptable firmness and colour values of tomatoes. J. Food Eng. 2004, 61, 471-475. [CrossRef]

33. Tilahun, S.; Park, D.S.; Taye, A.M.; Jeong, C.S. Effects of storage duration on physicochemical and antioxidant properties of tomato (Lycopersicon esculentum Mill.). Korea J. Hortic. Sci. Technol. 2017, 35, 88-97. [CrossRef]

34. Choi, H.R.; Tilahun, S.; Park, D.S.; Lee, Y.M.; Choi, J.H.; Baek, M.W.; Jeong, C.S. Harvest time affects quality and storability of kiwifruit (Actinidia spp.): Cultivars during long-term cool storage. Sci. Hortic. 2019, 256, 108523. [CrossRef]

35. Alda, L.M.; Gogoa, I.; Bordean, D.; Gergen, I.; Alda, S.; Moldovan, C.; Ni, L. Lycopene content of tomatoes and tomato products. J. Agroaliment. Process Technol. 2009, 15, 540-542.

36. Liu, L.; Wei, J.; Zhang, M.; Zhang, L.; Li, C.; Wang, Q. Ethylene independent induction of lycopene biosynthesis in tomato fruits by jasmonates. J. Exp. Bot. 2012, 63, 5751-5762. [CrossRef]

37. Hasturk Sahin, F.; Aktas, T.; Orak, H.; Ulger, P. Influence of pretreatments and different drying methods on color parameters and lycopene content of dried tomato. Bulg. J. Agric. Sci. 2011, 17, 867-881.

38. Mendelová, A.; Fikselová, M.; Mendel, L. Carotenoids and lycopene content in fresh and dried tomato fruits and tomato juice. Acta Univ. Agric. Silvic. Mendel. Brun. 2013, 61, 1329-1337. [CrossRef]

39. Farooq, S.; Rather, S.A.; Gull, A.; Ahmad Ganai, S.; Masoodi, F.A.; Mohd Wani, S.; Ganaie, T.A. Physicochemical and nutraceutical properties of tomato powder as affected by pretreatments, drying methods, and storage period. Int. J. Food Prop. 2020, 23, 797-808. [CrossRef] 
40. Chaudhary, P.; Sharma, A.; Singh, B.; Nagpal, A.K. Bioactivities of phytochemicals present in tomato. J. Food Sci. Technol. 2018, 55, 2833-2849. [CrossRef]

41. Silva-Beltrán, N.P.; Ruiz-Cruz, S.; Cira-Chávez, L.A.; Estrada-Alvarado, M.I.; Ornelas-Paz, J.D.J.; López-Mata, M.A.; Del-Toro-Sánchez, C.L.; Ayala-Zavala, J.F.; Márquez-Ríos, E. Tomatidine Contents and Antioxidant and Antimicrobial Activities of Extracts of Tomato Plant. Int. J. Anal. Chem. 2015, 2015, 1-10. [CrossRef]

42. Bhandari, S.R.; Chae, Y.; Lee, J.G. Assessment of phytochemicals, quality attributes, and antioxidant activities in commercial Tomato cultivars. Hortic. Sci. Technol. 2016, 34, 677-691. [CrossRef]

43. Martínez-Esplá, A.; Valero, D.; Martínez-Romero, D.; Castillo, S.; Giménez, M.J.; García-Pastor, M.E.; Serrano, M.; Zapata, P.J. Preharvest Application of Methyl Jasmonate as an Elicitor Improves the Yield and Phenolic Content of Artichoke. J. Agric. Food Chem. 2017, 65, 9247-9254. [CrossRef]

44. Barman, K.; Asrey, R. Salicylic acid pre-treatment alleviates chilling injury, Preserves bioactive compounds and enhances shelf life of mango fruit during cold storage. J. Sci. Ind. Res. 2014, 73, 713-718.

45. Frusciante, L.; Carli, P.; Ercolano, M.R.; Pernice, R.; Di Matteo, A.; Fogliano, V.; Pellegrini, N. Antioxidant nutritional quality of tomato. Mol. Nutr. Food Res. 2007, 51, 609-617. [CrossRef]

46. Slimestad, R.; Fossen, T.; Verheul, M.J. The flavonoids of tomatoes. J. Agric. Food Chem. 2008, 56, 2436-2441. [CrossRef]

47. Toor, R.K.; Savage, G.P. Effect of semi-drying on the antioxidant components of tomatoes. Food Chem. 2006, 94, 90-97. [CrossRef]

48. Yahia, E.M.; Contreras-Padilla, M.; Gonzalez-Aguilar, G. Ascorbic acid content in relation to ascorbic acid oxidase activity and polyamine content in tomato and bell pepper fruits during development, maturation and senescence. LWT Food Sci. Technol. 2001, 34, 452-457. [CrossRef]

49. Ahn, J.B. Amino Acid, Amino Acid Metabolite, and GABA Content of Three Domestic Tomato Varieties. Culin. Sci. Hosp. Res. 2016, 22, 71-77. [CrossRef]

50. Sorrequieta, A.; Ferraro, G.; Boggio, S.B.; Valle, E.M. Free amino acid production during tomato fruit ripening: A focus on L-glutamate. Amino Acids 2010, 38, 1523-1532. [CrossRef] [PubMed]

51. Pratta, G.; Zorzoli, R.; Boggio, S.B.; Picardi, L.A.; Valle, E.M. Glutamine and glutamate levels and related metabolizing enzymes in tomato fruits with different shelf-life. Sci. Hortic. 2004, 100, 341-347. [CrossRef]

52. Boggio, S.B.; Palatnik, J.F.; Heldt, H.W.; Valle, E.M. Changes in amino acid composition and nitrogen metabolizing enzymes in ripening fruits of Lycopersicon esculentum Mill. Plant Sci. 2000, 159, 125-133. [CrossRef] 